\title{
EDITORIAL \\ Prevention of vitamin D deficiency during infancy is achieved by a combination of low-dose maternal and infant supplementation
}

\author{
European Journal of Clinical Nutrition (2013) 67, 1010-1011; \\ doi:10.1038/ejcn.2013.153
}

Owing to concerns about adequacy of nutritional status and implications of maternal deficiency for both skeletal and non-skeletal health outcomes in mothers and babies, vitamin D nutrition during pregnancy and early childhood is the focus of intense interest among practitioners, scientists and the public. Vitamin D deficiency during pregnancy and infancy appears to be relatively common at Northerly latitudes; ${ }^{1}$ however, there is an absence of 25-hydroxyvitamin D (25OHD) reference data among sera collected from pregnant women at different gestational stages, from umbilical cords and from infants during the first 2 years. ${ }^{2,3}$ Recent narrative and systematic reviews on the impact of vitamin D on pregnancy ${ }^{2,4}$ and extra-skeletal health in children ${ }^{5}$ concluded that there are unconfirmed effects of 25OHD on preventing pregnancy complications ${ }^{4}$ and potentially serious adverse consequences of low maternal 250HD during pregnancy on the risk of childhood infectious diseases, which require investigation. ${ }^{5}$

Although controversy persists in relation to optimal serum 250HD concentrations for health promotion, most authoritative agencies now recommend maintenance of serum 25OHD concentrations $\geqslant 50 \mathrm{nmol} / \mathrm{l}$ on the basis of the evidence from systematic literature reviews to support normal skeletal growth and development during childhood and prevent aging-related bone demineralization during adulthood. ${ }^{1,6,7}$ The evidence basis for establishing target serum $25 \mathrm{OHD}$ concentrations on the basis of perinatal outcomes is inconclusive and largely based on observational studies; ${ }^{1,2,4,6}$ therefore, authorities have tended to extend recommendations for vitamin $D$ requirements among non-pregnant adults to pregnancy and lactation. Tracking target 25OHD concentrations back to dietary recommendations for vitamin $D$ is particularly challenging, and one of the issues highlighted by the US Institutes of Medicine (IOM), ${ }^{6}$ and other regulatory authorities, is the almost total lack of experimental data from studies designed to provide an estimate of the dietary intakes of vitamin D required to maintain serum $250 \mathrm{HD}$ above specified thresholds in pregnancy and early childhood. Thus, the current US Dietary Reference Interval (DRI) for pregnant and lactating women, at $15 \mu \mathrm{g}$ per day (600 IU), is the same as for non-pregnant women, on the basis that there were no data to presume otherwise. Similarly, scant data were available to set serum $25 \mathrm{OHD}$ targets during infancy, and for this reason the IOM established an Adequate Intake (AI) value, designated as an individual target in the absence of sufficient data to establish a DRI. The target value was based on evidence that maintaining serum $25 \mathrm{OHD}$ around $40-50 \mathrm{nmol} / \mathrm{l}$ was desirable, coupled with observational data suggesting that $10 \mu \mathrm{g}$ per day (400 IU) was adequate to maintain this level. ${ }^{6}$ ESPGHAN Committee on Nutrition ${ }^{1}$ has recently endorsed the pragmatic use of a serum $25 \mathrm{OHD}>50 \mathrm{nmol} / \mathrm{l}$ to indicate sufficiency and a serum concentration $<25 \mathrm{nmol} / \mathrm{l}$ to indicate severe deficiency and recommend that all infants should receive an oral supplementation of $10 \mu \mathrm{g}$ per day of vitamin D.
Despite fundamental knowledge gaps in relation to the doseresponse of vitamin D during pregnancy and infancy, increased transparency and widespread reliance on the systematic evaluation of the evidence basis among international agencies has increased harmonization with respect to authoritative vitamin D recommendations. One implication of this increased harmonization is that Clinical Research Ethics Boards would now be unlikely to approve implementation of a placebo-controlled doseresponse vitamin $D$ intervention study in infancy, and it appears that the window on a true placebo-controlled trial in babies has closed. Carefully conducted prospective observational studies, which include comprehensive data on the factors that determine the variability in circulating $25 \mathrm{OHD}$ among women and infants and the impact of habitual supplementation during pregnancy on maternal and infant 25OHD concentrations, such as the one described by vid Streym and colleagues ${ }^{8}$ in the current issue, are rare and make a valuable contribution to knowledge in this field.

The Aarhus-based study (latitude $56^{\circ} \mathrm{N}$ ) included 107 women and their 108 infants, who were followed up from delivery through to 9 months of age. ${ }^{8}$ Maternal and infant plasma 25OHD data are reported for three time points, at birth, 4 months and 9 months, and determinants of 250HD concentrations are quantified. The effect sizes of season, maternal 25OHD, maternal and infant supplement use and dose and maternal and infant BMI on plasma $250 \mathrm{HD}$ are reported, in addition to relevant biochemical data (parathyroid hormone (PTH), ionized calcium and creatinine). Meticulous reporting, sample handling and LCMS/MS analysis of 25OHD all contribute to quality evidence for the evaluation of the efficacy of low-dose supplementation in preventing maternal and infant vitamin $D$ deficiency in Caucasian women and infants resident at Northerly latitude.

The close association between maternal and umbilical cord plasma $250 H D$ levels, with maternal sampling close to delivery, confirmed previously described correlations. However, the prevalence of $250 \mathrm{OHD}<50$ and $25 \mathrm{nmol} / \mathrm{l}$ in mothers and cords reported in this study showed that among mothers with $250 \mathrm{HD}$ $<50 \mathrm{nmol} / \mathrm{l}$ the prevalence of cord plasma $<25 \mathrm{nmol} / \mathrm{l}$ was $66 \%$. Only one infant born to a mother with $250 \mathrm{HD}>50 \mathrm{nmol} / \mathrm{l}$ had a cord plasma concentration below $25 \mathrm{nmol} / \mathrm{l}$. Therefore, to prevent vitamin D deficiency (defined as $25 \mathrm{OHD} \leqslant 25 \mathrm{nmol} / \mathrm{l}$ ) in neonates in the Aarhus sample, the maternal $250 H D$ requirement at delivery was $\geqslant 50 \mathrm{nmol} / \mathrm{l}$. This observation has direct and profound implications for maternal 25OHD requirements during pregnancy. Specification of $25 \mathrm{OHD}$ requirements during gestation on the basis of maintaining fetal circulating $250 \mathrm{HD}$ at delivery at a minimum of $25 \mathrm{nmol} / \mathrm{l}$ would stipulate the attainment of serum $25 \mathrm{OHD} \geqslant 50 \mathrm{nmol} / \mathrm{l}$ in every pregnant woman. As an individual target, this is a completely different benchmark to recommending the achievement of a population average of $50 \mathrm{nmol} / \mathrm{l}$, or indeed the achievement of a low prevalence of $250 \mathrm{HD}$ below the average requirement of $40 \mathrm{nmol} / \mathrm{l}$, and has direct consequences for vitamin $D$ intake recommendations during pregnancy. A further consideration is that calcium intakes in the Aarhus cohort were likely to be high (measured but not reported), which may have had a $250 \mathrm{HD}$ sparing effect, and thus the individual target of $50 \mathrm{nmol} / \mathrm{l}$ implied by these data is based on adequate calcium nutrition. 
A high proportion of women in the Aarhus cohort used vitamin D supplements at a dose of $10 \mu \mathrm{g} /$ day during pregnancy, in line with Nordic recommendations for pregnant women to maintain intakes at or above $10 \mu \mathrm{g} / \mathrm{day}^{7}$ and there was a $25 \mathrm{nmol} / \mathrm{l}$ difference in $25 \mathrm{OHD}$ concentrations between mothers who reported using supplements and those who did not. The influence of maternal supplementation during pregnancy was apparent at delivery, with a difference of $10 \mathrm{nmol} / \mathrm{l}$ between cord $250 \mathrm{HD}$ levels in users versus non-users. More than $90 \%$ of infants also received a dose of $10 \mu \mathrm{g} / \mathrm{day}$, and this was associated with increasing 25OHD concentrations at 4 and 9 months compared with delivery. Daily supplementation at a dose of $10 \mu \mathrm{g}$ maintained plasma $25 \mathrm{OHD}$ levels above $50 \mathrm{nmol} / \mathrm{l}$ in $85-90 \%$ of infants up to 9 months, with up to $10 \%>125 \mathrm{nmol} / \mathrm{l}$. A surprising finding was the persistence of the influence of maternal $250 H D$ concentrations on infant $250 H D$ concentrations at 4 months, despite almost universal supplementation. Seasonal variability among infants was only apparent at 9 months of age. ${ }^{8}$

Data from the Aarhus cohort should be considered in the light of a recently reported randomized controlled trial by Gallo et al. ${ }^{9}$ in Montreal, as both have substantial implications for vitamin D requirements and recommendations during infancy. Briefly, Gallo et al..$^{9}$ implemented a dose-response study in 132 1-month-old infants ${ }^{9}$ to test the efficacy of vitamin D, at doses of 10, 20, 30 and $40 \mu \mathrm{g} /$ day, in maintaining $25 \mathrm{OHD}$ concentrations at 75 and $50 \mathrm{nmol} / \mathrm{l}$. Infants were followed up for 11 months. By 3 months, $55 \%$ of infants in the $10 \mu \mathrm{g}$ group and $80-100 \%$ of those in the higher doses had a $250 \mathrm{HD}$ level $\geqslant 75 \mathrm{nmol} / \mathrm{l}$, although these concentrations were not sustained over time. Almost all (97\%) infants in each of the four treatment groups achieved $50 \mathrm{nmol} / \mathrm{l}$ or higher at 3 months and almost everyone sustained this to 12 months. Growth and bone mineral content did not differ by dosage. The authors discontinued the $40 \mu \mathrm{g} /$ day dose prematurely because almost all infants on this dose had serum 25OHD concentrations $\geqslant 250 \mathrm{nmol} / \mathrm{l}$ by 3 months of age, although these concentrations were not associated with any adverse effects. ${ }^{9}$

The observational data reported in the current issue by the Aarhus group ${ }^{8}$ and the intervention data from the Montreal group 9 complement each other and provide additional evidence to support the recent recommendations for vitamin D in infancy from authoritative agencies. ${ }^{1,6,7}$ It currently appears that $10 \mu \mathrm{g} /$ day of vitamin $D$ among healthy infants is safe and effective in achieving a circulating $25 \mathrm{OHD} \geqslant 50 \mathrm{nmol} / \mathrm{l}$. Although further studies are required in toddlers and older children to better define vitamin D requirements among these age groups, ${ }^{3}$ these data should help increase harmonization among national and international agencies with respect to vitamin D recommendations for deficiency prevention in infancy. The Aarhus data show that maintenance of $250 \mathrm{HD} \geqslant 50 \mathrm{nmol} / \mathrm{I}$ during pregnancy (in a well-nourished and calcium-replete population) prevents neonatal deficiency, defined as $25 \mathrm{OHD}$ $<25 \mathrm{nmol} / \mathrm{l}$, and this has direct consequences for $25 \mathrm{OHD}$ requirements and vitamin $D$ recommendations during pregnancy. Dose-response intervention studies among pregnant women, of variable ethnic backgrounds and calcium intakes, including quality bio-banking of umbilical cord serum and, ideally, post-natal follow-up, are urgently required.

\section{CONFLICT OF INTEREST}

The author declares no conflict of interest.

M Kiely

Vitamin D Research Group, School of Food and Nutritional Sciences, University College Cork, Cork, Ireland E-mail: m.kiely@ucc.ie

\section{REFERENCES}

1 Braegger C, Campoy C, Colomb V, Decsi T, Domellof M, Fewtrell M et al. on Behalf of the ESPGHAN Committee on Nutrition. Vitamin D in the healthy European paediatric population. J Pediatr Gastroenterol Nutr 2013; 56: 692-701.

2 Brannon PM, Picciano MF. Vitamin D in pregnancy and lactation in humans. Annu Rev Nutr 2011; 31: 89-115.

3 Cashman KD, Kiely M. Towards prevention of vitamin D deficiency and beyond: knowledge gaps and research needs in vitamin $\mathrm{D}$ nutrition and public health. Br J Nutr 2011; 106: 1617-1627.

4 Christesen HT, Falkenberg T, Lamont RF, Jørgensen JS. The impact of vitamin D on pregnancy: a systematic review. Acta Obstet Gynecol Scand 2012; 91: 1357-1367.

5 Christesen HT, Elvander C, Lamont RF, Jørgensen JS. The impact of vitamin D in pregnancy on extraskeletal health in children: a systematic review. Acta Obstet Gynecol Scand 2012; 91: 1368-1380.

6 Institute of Medicine. Dietary Reference Intakes for Calcium and Vitamin D. The National Academies Press: Washington, DC, 2011.

7 Nordic Nutrition Recommendations 2012. 5th edition draft proposal: Vitamin D. Accessed from: http://www.slv.se/upload/NNR5/Vitamin\%20D\%20NNR\%202012. pdf. (26th June 2013).

8 vid Streym S, Møller UK, Rejnmark L, Heickendorff L, Mosekilde L, Vestergaard P. Maternal and infant vitamin $D$ status during the first 9 months of infant life-a cohort study. Eur J Clin Nutr 2013; 67: 1022-1028.

9 Gallo S, Comeau K, Vanstone C, Agellon S, Sharma A, Jones G et al. Effect of different dosages of oral vitamin $D$ supplementation on vitamin $D$ status in healthy, breastfed infants: a randomized trial. JAMA 2013; 309: 1785-1792. 